\title{
FUNGI ASSOCIATED WITH ROOT AND CROWN ROT OF WHEAT IN THE KERMAN PROVINCE OF IRAN
}

Maryam Rouzbeh, Gholam Reza Baradaran

Plant Protection Research Department, Kerman Agricultural and Natural Resources Research and Education Center, AREEO, Kerman, Iran.

ART I CLE IN F O

\section{Article history}

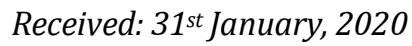

Revised: $19^{\text {th }}$ March, 2020

Accepted: 22 $2^{\text {nd }}$ March, 2020

\section{Keywords}

Wheat root rot

Fusarium spp.

Pathogenicity

Bipolaris spp.

Drechslera spp.

\section{A B S T R A C T}

\begin{abstract}
In the growing season of 2016-17, the fungal agents associated with crown and root rot of wheat in the Kerman province of Iran were identified. For this purpose, different fields were randomly selected for sampling and percentages of disease were estimated. Infected parts of root and crown were surface sterilized and cultured on Potato Dextrose Agar medium. A total of 260 isolates were obtained and identified on the basis of macroscopic and microscopic characters and valid keys. Of the total isolates, 212 belonged to Fusarium, 28 to Bipolaris and 20 isolates belonged to Drechslera species. Fungal species included F. oxysporum (96 isolates), F. nivale (20 isolates), F. poae (18 isolates), F. anthophilum (9 isolates), F. subglutinans (22 isolates), F. solani (32 isolates), F. culmorum (11 isolate), F. proliferatum (2 isolate), F. chlamydosporum (2 isolates), B. kusanoi (11 isolates), $B$. australiensis (17 isolates) and $D$. tetrarrhene (20 isolates). The pathogenicity test was conducted using greenhouse root dip technique. The pathogenicity confirmed five Fusarium species, two Bipolaris and one Drechslera species associated with wheat root and crown rot in Kerman province of Iran. It is concluded that wheat root and crown rot is fairly distributed in the Kerman province and showed virulence of varying degrees demanding strict control measures to minimize losses.
\end{abstract}

Corresponding Author: Maryam Rouzbeh

Email: maryam.rouzbeh@gmail.com

(c) 2020 EScience Press. All rights reserved.

\section{INTRODUCTION}

Wheat (Triticum aestivum L.) is the most important crop in the world, particularly in Iran. Wheat crown and root rot is one of the most common diseases in wheat growing regions around the world which has led to a decline in annual yields (Mohammadipour and Ilkhechi, 2004). The term common crown and root rot is often used to refer to a group of complex disease that is characterized by blighting, stunting and death of seedling, stunting of mature plants, necrotic lesions on seminal and crown roots, sub-crown internodes, crown and stem tissue (Sallans, 1965). Common root and crown rot is caused by several soil borne pathogens. Species of Bipolaris and Drechslera have roles for inducing foot and root decays. Bipolaris sorokiniana is distributed worldwide in all of the major cereal growing regions. Within a region, it is rare to find a field that does not harbor the pathogen at some level of inoculum (Mathre et al., 2003). Two species of Bipolaris were identified as B. sorokiniana and B. australiensis. The first 
one had highest prevalence and the latter had lowest prevalence. B. australiensis was isolated from wheat root in Damghan and this was the first report of this pathogen on wheat root from Iran (Ommaty et al., 2000). In the other study, three species including $B$. australiensis, B. kusanoi and Drechslera tetrrahene were identified from wheat fields of Kerman province (Hashemi et al., 2011).

Several species of Fusarium are common causative agents of brown rot of cereals, especially in temperate and semi-tropical areas (Hajieghrari, 2009). Fusarium crown rot has been reported from all wheat cultivating areas including Australia, North America, Africa and China. Identification and pathogenicity of Fusarium spp. isolated from wheat fields in Queensland and Northern New South Wales appeared to be increasingly important globally in part, at least, because resistant wheat varieties are commercially unavailable (Beccari et al., 2018).

Another study in Turkey showed the existence of a wide range of Fusarium species associated with crown rot of wheat. F. culmorum, F. pseudograminearum and $F$. graminearum caused severe crown rot disease on durum wheat. $F$. avenaceum and $F$. hostae were weakly to moderately virulent (Gebremariam et al., 2018). Several species of Fusarium (F. culmorum, F. nivale, F. solani, $F$. oxysporum, F. solani, F. oxysporum, F. subglutinans, F. reticulatum, $F$. anthophilum, $F$. chlamidosporum, $F$. proliferatum and $F$. poae) were detected from wheat fields of Kerman province of Iran (Dehghan et al., 2011). Similarly, two species of Curvularia (C. ramose and $C$. specie-do) were included in the common root rot and crown rot complex (Sallans, 1965).

Take-all of wheat is caused by the fungus, Gaeumannomyces graminis var. tritici. It is the deadliest root disease of wheat worldwide. It also affects triticale, barley and rye but to a lesser extent (Freeman and Ward, 2004) and causes stunting and nutrient deficiency symptoms in the tops and progresses upward into the bases of the stems. Here, it disrupts the flow of water to the tops and causes premature death of the plant (Cook, 2003).

Rhizoctonia solani Kuhn anastomosis group eight (AG8) caused "bare patch", colonized the roots of wheat producing symptoms of stunted shoot growth, whitehead, reduced blackened roots and premature grain ripening. It is more severe in sandy soils where rainfall is low (Gill et al., 2000). The present research is focused on the identification and pathogenicity of fungal pathogens associated with wheat root and crown rot compared to previous study in 2009 in the Kerman province of Iran.

\section{MATERIALS AND METHODS}

Sampling: The sampling was done during the growing season of 2016-17 from wheat farms in the Kerman province of Iran. A total of 260 samples of durum and bread wheat from four regions were collected. Plants in ripe maturity stages with dubious symptoms such as necrosis, weakness, yellowing, and white heading were collected randomly (about 2- $3 \mathrm{~km}$ apart), placed in plastic bags and taken to the laboratory.

\section{Isolation of wheat root and crown associated fungi:}

The wheat root and crown collected samples were washed under tap water. The infested roots, lower crown internodes and crown pieces (3-5 mm) were surface disinfected by immersing in $2 \%$ sodium hypochlorite solution for 2-3 minutes. They were washed twice in sterile distilled water and dried on sterile filter paper in a laminar airflow cabinet (Heydarian and Ershad, 2000). Specimens were cultured on Potato Dextrose Agar (PDA) in $9 \mathrm{~cm}$ Petri dishes and incubated at $25^{\circ} \mathrm{C}$. Emerging fungi were subcultured on PDA and purified by hyphal tip and single spore culture.

Identification of common root and crown rot fungi: Fusarium cultures were transferred to Carnation Leaf Agar (CLA). The cultures were identified on the basis of general colony morphology, mycelial morphology, reproductive structure and taxonomic description. Fusarium spp. were characterized by macroscopic features such as colony morphology and color and microscopic morphological characteristics of microconidia, macroconidia, chlamydospores and conidiophores of the Fusarium diagnostic keys (Booth, 1971; Leslie and Summerell, 2008; Nelson et al., 1983; Nirenberg, 1990). Bipolaris spp. isolates were characterized by a profuse production of Bipolaris-type dark conidia identified with a binocular microscope and the species were identified according to their description (Ellis, 1971; Sivanesan, 1987). The germination of conidia produced on PDA was also examined, using dispersed conidia in a drop of sterilized water on the surface of PDA plates (Hajieghrari, 2009). To identify and differentiate Bipolaris and Drechslera species, germination of conidia was studied. Conidia were dispersed in a drop of sterilized water on the surface 
of PDA; plates were then placed under alternative light for 4-5 days. After stipulated period, the germination of conidia was examined with light microscope.

Pathogenicity test: For pathogenicity test, two wheat species were used in the tropical zone such as durum wheat (Triticum durum) var. Shabrang and bread wheat (Triticum aestivum) var. Chamran. In temperate zone, bread wheat var. Mihan was used. These varieties predominate in the tropical and temperate zones. Root dip method was used to determine the pathogenicity of all the fungi. Wheat seeds were disinfected with $1 \%$ sodium hypochlorite for 5 min followed by rinsing with distilled water 3 times and then sown in the sterilized sand. After germination, plants were removed from the sand and roots were washed with distilled water. Subsequently, the conidia of fungi were scraped off from the surface of Potato Dextrose Agar (PDA, Merck.39 g/l) and counted, using hemocytometer. They were adjusted to $10^{6}$ conidia/ml.

The washed roots were placed in conidial suspension of $10^{6}$ conidia for 24 hours. For control pots, the roots were placed in distilled water until 24 hours (Heydarian and Ershad, 2000). Treated seedlings were planted in the sterilized sand and pots were randomly placed in the greenhouse. There were five replicates for each isolate. After four weeks, seedlings were evaluated. The root and crown inoculated plants were scored after decay and color change using 0 to 5 scale. The scale depends on the browning percentage on the basal stem i.e. $1=1-9 \%, 2=$ $10-29 \%, 3=30-69 \%, 4=70-89 \%$ and $5=90-99 \%$. The lines were ranked from resistant to highly susceptible as follow; $\mathrm{R}=$ Resistant, $\mathrm{MR}=$ Moderately Resistant, $\mathrm{MS}=$ Moderately Susceptible, $\mathrm{S}=$ Susceptible, HS = Highly Susceptible (Sudhir, 2015).

\section{RESULTS}

Of the total 260 recovered isolates, three genera viz. Fusarium, Bipolaris and Drechslera were identified with frequencies of 212, 28 and 20 respectively. Out of total 212 Fusarium isolates, 9 Fusarium species were recognized. These species included $F$. oxysporum, $F$. nivale, F. poae, F. anthophilum, F. subglutinans, F. solani, $F$. culmorum, $F$. proliferatum and F. chlamydosporum. Two Bipolaris species consisting of B. kusanoi and $B$. australiensis and one Drechslera species, D. tetrarrhenae, were identified.

The infection of the disease ranged from $2.1 \%$ to $14.5 \%$ in the 52 areas of study. Fusarium spp. were found predominant that caused root and crown rot. The species were isolated from wheat crown and root tissue from different districts in Kerman province. Two species i.e. F. oxyspurum and F. solani were the most commonly isolated from wheat crown and root isolates. These species of Fusarium may happen individually or in conjunction with other recognized species of Fusarium and in some areas with other specified fungi. With the exception of four species of Fusarium, most of the isolated fungi were pathogens. Based on greenhouse pathogenicity trials, Fusarium species i.e. F. oxysporum, F. nivale, F. culmorum, F. poea and Bipolaris kusanoi, B. australiensis and $D$. tetrarrhenes were virulent at varying degrees (Table 1, 2, 3).

Table1: Fungi associated with root and crown rot of durum wheat var. Shabrang from tropical zone.

\begin{tabular}{lcccccc}
\hline \multicolumn{1}{c}{ Fungal Species } & \multirow{2}{*}{$\begin{array}{l}\text { Pathogenicity } \\
\text { test }\end{array}$} & $\begin{array}{c}\text { Severity } \\
\text { Index }\end{array}$ & & \multicolumn{4}{c}{ Number of positive isolates in } \\
\cline { 4 - 7 } F. oxysporum & + & 4 & 8 & 8 & 7 & Dakilabad \\
F. nivale & + & 4 & 2 & 2 & 0 & 2 \\
F. poae & + & 4 & 3 & 2 & 2 & 2 \\
F. anthophilum & - & 0 & 2 & 0 & 0 & 2 \\
F. subglutinans & - & 0 & 2 & 2 & 2 & 1 \\
F. solani & + & 4 & 2 & 2 & 2 & 2 \\
F. culmorum & + & 5 & 1 & 0 & 0 & 12 \\
F. proliferatum & - & 0 & 0 & 0 & 0 & 0 \\
B. kusanoi & + & 4 & 1 & 1 & 0 & 2 \\
B. australiensis & + & 4 & 2 & 2 & 2 & 2 \\
D. tetrarrhene & + & 4 & 2 & 2 & 2 & 2 \\
\hline
\end{tabular}

The scale depending on the browning percentage on the basal stem $1=1-9 \%, 2=10-29 \%, 3=30-69 \%, 4=70-89 \%$ and $5=90-99 \%$. 
Table 2: Fungi associated with root and crown rot of bread wheat var. Chamran from tropical zone.

\begin{tabular}{lcccccc}
\hline \multirow{2}{*}{ Fungal Species } & \multicolumn{2}{c}{$\begin{array}{l}\text { Pathogenicity } \\
\text { test }\end{array}$} & Severity & \multicolumn{4}{c}{ Number of positive isolates in } \\
\cline { 4 - 7 } & & Index & Vakilabad & Shahmaran & Soghan & Dolatabad \\
\hline F. oxysporum & + & 4 & 11 & 11 & 8 & 8 \\
F. nivale & + & 5 & 2 & 5 & 2 & 5 \\
F. poae & + & 5 & 3 & 2 & 2 & 2 \\
F. anthophilum & - & 0 & 2 & 0 & 1 & 2 \\
F. subglutinans & - & 0 & 2 & 2 & 2 & 1 \\
F. solani & + & 5 & 2 & 4 & 2 & 4 \\
F. culmorum & + & 5 & 2 & 0 & 0 & 2 \\
F. proliferatum & - & 0 & 2 & 0 & 0 & 0 \\
B. kusanoi & + & 5 & 1 & 1 & 0 & 1 \\
B. australiensis & + & 5 & 3 & 2 & 2 & 2 \\
D. tetrarrhene & + & 5 & 2 & 2 & 2 & 2 \\
\hline
\end{tabular}

The scale depending on the browning percentage on the basal stem $1=1-9 \%, 2=10-29 \%, 3=30-69 \%, 4=70-89 \%$ and $5=90-99 \%$.

Table 3: Fungi associated with root and crown rot of bread wheat var. Mihan from temperate zone.

\begin{tabular}{|c|c|c|c|c|c|c|c|}
\hline \multirow{2}{*}{ Fungal Species } & \multirow{2}{*}{$\begin{array}{l}\text { Pathogenicity } \\
\text { test }\end{array}$} & \multirow{2}{*}{$\begin{array}{l}\text { Severity } \\
\text { Index }\end{array}$} & \multicolumn{5}{|c|}{ Number of positive isolates in } \\
\hline & & & Baft & Bardsir & Negar & Mahan & Shahrbabak \\
\hline F. oxysporum & + & 3 & 6 & 6 & 6 & 4 & 2 \\
\hline F. solani & + & 5 & 4 & 2 & 2 & 2 & 2 \\
\hline F. culmorum & + & 5 & 2 & 2 & 0 & 0 & 0 \\
\hline F. subglutinans & - & 0 & 2 & 2 & 2 & 2 & 0 \\
\hline F. chlamidosporum & - & 0 & 0 & 12 & 0 & 0 & 0 \\
\hline B. kusanoi & + & 5 & 1 & 2 & 1 & 1 & 0 \\
\hline D. tetrarrhene & - & 0 & 2 & 2 & 0 & 0 & 0 \\
\hline
\end{tabular}

The scale depending on the browning percentage on the basal stem $1=1-9 \%, 2=10-29 \%, 3=30-69 \%, 4=70-89 \%$ and $5=90-99 \%$.

\section{DISCUSSION}

Results from the study of wheat farms in Kerman province showed that root and crown rot is a major disease in these farms resulting in yield losses by causing damping off, decreasing number of tillers, head size and seed yields. Wheat crown and root rot problem was caused by multiple fungi. Among these fungi, the species of Fusarium were found to be the most prevalent of all the associated fungi and are in line with the findings of Gonzalez and Trevathan (2000). The most common infection in wheat fields was due to Fusarium genus which comprises about $76 \%$ of isolated fungi whereas results of other studies in these districts in 2011 showed that 99\% of isolates were Fusarium (Dehghan et al., 2011). The prevalence and frequency differentiation of the genus Fusarium and certain species in a region is also primarily affected by crop rotation and environmental circumstances, especially temperature and humidity requirements. The results showed that the frequency of isolates in the tropical zone between varieties was similar. $F$. nivale, $F$. poae and $F$. proliferatum exist in the tropical zone and $F$. chlamidosporum exists only in the temperate zone. Three species $F$. oxysporum, $F$. solani and $F$. subglutinans were the most prevalent in each case. Forty eight of the isolates in the present study belonged to two species of Bipolaris and one that to Drechslera.

In the present study, B. kusanoi, B. australiensis and $D$. tetrarrhene were isolated from tropical zone and B. kusanoi and $D$. tetrarrhene were isolated from temperate zone. The present findings are similar to the reports of different regions of world and Iran (Fedel-Moen and Harris, 1987; Hekimhan et al., 2004; Kazemi, 2001; Moradzadeh et al., 1997; Van, 2004; Zare and Ershad, 1997).

The population of Bipolaris, Drechslera and Fusarium species was boosted in this research compared to the 
previous research conducted by Dehghan et al. (2011). The reason of this increase is change in irrigation method i.e. from flood irrigation to sprinkler and tap drip irrigation in recently years. These new methods decreased irrigation interval (4-6 days) compared to traditional irrigation (10- 15 days), therefore, soil remained wet for a long time. The prevalence of Bipolaris and Drechslera were reported in South Asia at high temperature and humidity (Kumar et al., 2002). The present studies also show that Fusarium infection increases at high humidity and corroborated the findings of Gherbawy et al. (2006).

It is concluded that wheat root and crown rot is fairly distributed in the Kerman province of Iran. The fungi associated with this disease were $F$. oxysporum, F. nivale, F. culmorum, F. poea, Bipolaris kusanoi, B. australiensis and Drechslera tetrarrhenes. The fungi showed virulence of varying degrees and demand strict control measures to minimize losses.

\section{ACKNOWLEDGEMENTS}

The authors greatly acknowledge Kerman Agricultural and Natural Resources Research and Education Center, AREEO, Kerman, Iran for assisting to carry out the study.

\section{CONFLICT OF INTEREST}

The authors declare no conflict of interest.

\section{AUTHORS' CONTRIBUTION}

MR and GRB designed the study, executed the experiment, collected and analyzed the data, wrote and edited the manuscript. Both the authors approved the final manuscript.

\section{REFERENCES}

Beccari, G., Prodi, A., Pisi, A., Nipoti, P., Onofri, A., Nicholson, P., Pfohl, K., Karlovsky, P., Gardiner, D.M., Covarelli, L., 2018. Development of three Fusarium crown rot causal agents and systemic translocation of deoxynivalenol following stem base infection of soft wheat. Plant Pathology 67, 1055-1065.

Booth, C., 1971. The genus Fusarium. Commonwealth Mycological Institute Kew, Surrey UK.

Cook, R.J., 2003. Take-all of wheat. Physiological and Molecular Plant Pathology 62, 73-86.

Dehghan, S., Hashemi, M., Baradaran, G., 2011. Isolation and identification of Fusarium species, associated with root and crown rot of wheat in Kerman province, Asian Mycological Congress 2011 and 12th International Marine and Fresh Water Mycology Symposium, Incheon, Korea, p. 251.
Ellis, M.B., 1971. Dematiaceous Hyphomycetes. Commonwealth Mycological Institute, Kew.

Fedel-Moen, R., Harris, J.R., 1987. Stratified distribution of Fusarium and Bipolaris on wheat and barley with dryland root rot in South Australia. Plant Pathology 36, 447-454.

Freeman, J., Ward, E., 2004. Gaeumannomyces graminis, the take-all fungus and its relatives. Molecular Plant Pathology 5, 235-252.

Gebremariam, E.S., Sharma-Poudyal, D., Paulitz, T.C., Erginbas-Orakci, G., Karakaya, A., Dababat, A.A., 2018. Identity and pathogenicity of Fusarium species associated with crown rot on wheat (Triticum spp.) in Turkey. European Journal of Plant Pathology 150, 387-399.

Gherbawy, Y.A.M.H., Maghraby, T.A., Shebany, Y.M., 2006. Seasonal variations of Fusarium species in wheat fields in upper Egypt. Archives of Phytopathology and Plant Protection 39, 365-377.

Gill, J.S., Sivasithamparam, K., Smettem, K.R.J., 2000. Soil types with different texture affects development of Rhizoctonia root rot of wheat seedlings. Plant and Soil 221, 113-120.

Gonzalez, M.S., Trevathan, L.E., 2000. Identity and pathogenicity of fungi associated with root and crown rot of soft red winter wheat grown on the upper coastal plain land resource area of Mississippi. Journal of Phytopathology 148, 77-85.

Hajieghrari, B., 2009. Wheat crown and root rotting fungi in Moghan area, Northwest of Iran. African Journal of Biotechnology 8, 6214-6219.

Hashemi, M., Dehghan, S., Baradaran, G., 2011. Isolation and identification of Bipolaris and Drechslera species, associated with root and crown rot of wheat in Kerman province, Asian Mycological Congress 2011 and 12th International Marine and Fresh Water Mycology Symposium, Incheon, Korea, p. 252.

Hekimhan, H., Bagci, A., Nicol, J., Arisoy, Z., Taner, S., Sahin, S., 2004. Dryland root rot: A major threat to winter cereal production under sub-optimal growing conditions, Proceedings of the 4th International Crop Science Congress, p. 283.

Heydarian, A., Ershad, J., 2000. Identification of wheat crown and rot fungi in Chaharmahal and Bakhtiari province. Plant Pathology 37, 97-114.

Kazemi, H., 2001. Fusarium species with wheat crown and root in Tehran province. , Proceeding of the 
15th Iranian Plant Protection, p. 35.

Kumar, J., Schäfer, P., Hückelhoven, R., Langen, G., Baltruschat, H., Stein, E., Nagarajan, S., Kogel, K., 2002. Bipolaris sorokiniana, a cereal pathogen of global concern: cytological and molecular approaches towards better control. Molecular Plant Pathology 3, 185-195.

Leslie, J.F., Summerell, B.A., 2008. The Fusarium laboratory manual. John Wiley \& Sons.

Mathre, D.E., Johnston, R.H., Grey, W.E., 2003. Diagnosis of common root rot of wheat and barley. Plant Health Progress 4, 1-6.

Mohammadipour, M., Ilkhechi, A.D., 2004. Etiology and distribution of fungal diseases of wheat root and foot rot in east Azerbaijan, Joint Agriculture and Natural Resources Symposium, Tabriz, Ganja, Iran, pp. 1-3.

Moradzadeh, E., Falahati, M., Rastgar, M., Jafarpour, B., 1997. Identification, pathogenicity and distribution of Fusarium species with wheat crown and root rot in Khorasan province, 13th Iranian Plant Protection Congress, Iran.

Nelson, P.E., Toussoun, T.A., Marasas, W.F.O., 1983. Fusarium species: an illustrated manual for identification. Pennsylvania State University.
Nirenberg, H.I., 1990. Recent advances in the taxonomy of Fusarium. Studies in Mycology, 91-101.

Ommaty, F., Golzar, H., Nagafi, N.H., Mohamadi, I., 2000. Identification and prevalence of Bipolsris and Drechslera, the causal agent of foot and root rot of winter wheat in some provinces of Iran. Agricultural Science and Technology Information, Food and Agriculture Organization of the United Nations, Italy.

Sallans, B.J., 1965. Root rots of cereals. III. The Botanical Review 31, 505-536.

Sivanesan, A., 1987. Graminicolous species of Bipolaris, Curvularia, Drechslera, Exserohilum and their teleomorphs. Centre for Agriculture and Bioscience International.

Sudhir, S., 2015. Enhancing resistance in high yielding adapted germplasm to major wheat soil borne diseases. Internaional Maize and Wheat Improvement Center, p. 18.

Van, D.K., 2004. Fungi associated with root and crown rot of wheat and barley in Tanzania. African Plant Protection 10, 117-124.

Zare, R., Ershad, D., 1997. Fusarium species isolated from cereals in Gorgan area. Iranian Journal of Plant Pathology 33. 